\title{
Thermo-Mechanical Properties of an NiTi-Shape Memory Alloy after Dynamic Loading
}

\author{
V. Grigorieva, A. DAnilov and A. Razov*
}

Saint-Petersburg State University, Universitetskii pr. 28, Saint-Petersburg, 198504, Russia

\begin{abstract}
The results of the comparative study of a quasi-equilibrium NiTi alloy's thermo-mechanical response to highrate and quasi-static straining in the temperature range of $100-300{ }^{\circ} \mathrm{C}$, which included the $A_{\mathrm{f}}$ and the $M_{\mathrm{d}}$ temperatures, are considered. The existence of $B 2 \rightarrow B 19^{\prime}$ and $B 2 \rightarrow R \rightarrow B 19^{\prime}$ martensitic transformations, associated with the heterogeneous distribution of $\mathrm{Ni}_{4} \mathrm{Ti}_{3}$ precipitates is shown to result in shaping of martensitic and austenitic two-way shape memories, the simultaneous presence of which determines the reversing shape memory effect. The suppression of stress-induced $B 2 \rightarrow B 19^{\prime}$ transformation at temperatures higher than the $M_{\mathrm{d}}$ temperature resulted in austenitic two-way shape memory only. Distinct dependences on the temperature of the critical stresses that initiate $B 2 \rightarrow B 19^{\prime}$ and $B 2 \rightarrow R \rightarrow B 19^{\prime}$ martensitic transformations in austenite are shown to be the reason for the participation of the irreversible mechanisms of straining at the earliest stages of tension, whatever the strain-rate applied, thus annihilating the distinctions between the quasi-static and high-rate straining processes. As a result, the thermo-mechanical properties acquired after tension become practically independent of the strain-rate.
\end{abstract}

DOI: 10.12693 /APhysPolA.128.592

PACS: $62.20 . \mathrm{fg}, 81.30 . \mathrm{Kf}, 81.70 . \mathrm{Bt}$

\section{Introduction}

The study of the thermo-mechanical response of nickel-titanium alloys to high strain rate loading has attracted particular interest because of the intensive trials to apply these materials as sensors and actuators for civil engineering and airspace techniques, where the high and stable functional properties of $\mathrm{NiTi}$ devices are in great demand $[1,2]$.

The fact that the high stress amplitudes of the shortterm loads tend to vary the mechanical and functional properties of a device determines the complexity of such applications. At least to decrease the effect of the exploiting temperature on the structural stability (and thus on functional properties) of the devices, the alloys' ageing is applied as an ultimate technological operation, which results in the creation of a quasi-equilibrium structure that is more stable with variations in the external temperature.

The structural peculiarities of the quasi-equilibrium state of the NiTi alloys and general regularities of their response to high-rate loading at temperatures in the range of $20-300{ }^{\circ} \mathrm{C}$ were described and discussed earlier [3-6]. Briefly, the martensitic transformation in such an alloy revealed a three-stage character associated with heterogeneous distribution of $\mathrm{Ni}_{4} \mathrm{Ti}_{3}$ precipitates. Two stages were caused by the $B 2 \rightarrow R \rightarrow B 19^{\prime}$ transformation that took place in the areas close to the grain boundaries enriched with the precipitates, and one stage - by the $B 2 \rightarrow B 19^{\prime}$ transformation that took place in the interior of a grain free of precipitates $[7,8]$. Thermo-cycling

* corresponding author; e-mail: a.razov@spbu.ru of unstrained and unloaded quasi-equilibrium NiTi specimens through the interval of martensitic transformations demonstrated the reversing strain behaviour upon cooling [5]. From the comparative analysis of experimental data obtained in high-rate and quasi-static tension it could be concluded that the strain rate did not change the basic structural mechanisms of straining [4]. The observed distinctions in the mechanical responses to the high-rate and quasi-static tension of the alloy in the martensitic and two-phase states were interpreted as the result of distinct sequences of the acting reversible and irreversible structural mechanisms of straining [6]. In particular, the generation of dislocations at the earliest stages of high-rate straining in comparison with quasistatic straining, where dislocation plasticity joined the deformation process at the latest stages, reduced the completeness of the reversible mechanisms' realization and thus led to lower magnitudes of one-way and twoway shape memory effects (OWSME and TWSME) after high-rate tension. The more pronounced self-heating of specimens on the high-rate straining was shown to cause a narrowing of the temperature range of the one-way shape memory exhibition and shifted the corresponding OWSME and TWSME dependences on the test temperature to lower temperatures. The above relationship between functional properties after quasi-static and highrate tension was violated at test temperatures higher than the $A_{\mathrm{f}}$ temperature. Both types of tension in the range of the $A_{\mathrm{f}}$ to $M_{\mathrm{d}}$ temperatures resulted in almost equal magnitudes of strains associated with the OWSME and TWSME.

The aim of the present study was to clarify the details of the high-rate and quasi-static tension of a quasiequilibrium NiTi alloy in fully austenitic state by analyzing the OWSME and TWSME, acquired after both sets 
of experiments in the temperature range of $100-300^{\circ} \mathrm{C}$ that involved the $A_{\mathrm{f}}$ and $M_{\mathrm{d}}$ temperatures. Thus the processes of the high-rate and the quasi-static straining at temperatures lower than the $M_{\mathrm{d}}$ temperature assumed the participation of reversible (stress-induced martensitic transformations) mechanisms, while at temperatures higher than the $M_{\mathrm{d}}$ temperature only the irreversible (generation and sliding of dislocations) mechanisms were assumed to act.

\section{Material and experiment}

The cylindrical specimens (with operative parts of $5 \mathrm{~mm}$ in diameter and $10 \mathrm{~mm}$ in length) for high-rate and quasi-static tension were made of a binary NiTi alloy hotrolled rods. To remove the residual stress and to create the quasi-equilibrium structure, we used ageing at $500{ }^{\circ} \mathrm{C}$ for $1 \mathrm{~h}$ followed by cooling in a furnace. The characteristic temperatures of the forward and reverse martensitic transformations were determined in a differential scanning calorimeter (DSC) Mettler Toledo 822e. The heating and cooling rates during DSC measurements were 10 degree/min. Transformation temperatures, determined from DSC peaks with a slope extension method, were as follows: $M_{\mathrm{s}}=74^{\circ} \mathrm{C}, M_{\mathrm{f}}=32^{\circ} \mathrm{C}, A_{\mathrm{s}}=74^{\circ} \mathrm{C}$, $A_{\mathrm{f}}=98^{\circ} \mathrm{C}$. The characteristic $M_{\mathrm{d}}$ temperature, determined in [3] as a cross-point of the plots $\sigma_{\max }$ - the maximal stress achieved at the first stage of the high-rate tension, and $\sigma_{\mathrm{ph}}$ - the phase yield threshold of the austenite, as functions of test temperature, was about $160^{\circ} \mathrm{C}$.

The high-rate tension at a strain rate of about $10^{3} \mathrm{~s}^{-1}$ in the temperature range of $100-300^{\circ} \mathrm{C}$ was performed, using the modified split Hopkinson pressure bar (SHPB) technique [9]. The quasi-static tension at a strain rate of $10^{-3} \mathrm{~s}^{-1}$ in the same temperature range was executed in the universal machine for mechanical tests "Lloyd 30K Plus", equipped with a thermal chamber. Residual strain $\varepsilon_{\text {res }}$ was from 15 to $25 \%$.

To analyze the functional properties of the alloy specimens after both types of tension, the heating/cooling cycling through the temperature range of martensitic transformations without external load was conducted in a special device [10]. The heating and cooling rates in this case were 1-2 degree/min. The magnitude of the strain restored, which characterized the shape memory effect of the alloy after high-rate and quasi-static tension, was determined on heating, while the magnitude of the accumulated strain, which characterized the induced two-way shape memory effect, was controlled on cooling.

\section{Results and discussion}

Figures 1-3 demonstrate the deformation behaviour of the unloaded specimens in the first and second heating/cooling cycles after quasi-static and high-rate tension at temperatures below (Figs. 1 and 2) and above (Fig. 3) the $M_{\mathrm{d}}$ temperature. The more pronounced temperature rise caused by high-rate straining was taken into consideration when comparing the deformation behaviour after the quasi-static and the high-rate tension (the real temperatures of the specimens heated up to $110^{\circ} \mathrm{C}$ and $130^{\circ} \mathrm{C}$ before high-rate tension in Fig. 2 during tests were approximately $130^{\circ} \mathrm{C}$ and $150^{\circ} \mathrm{C}$ ), so the temperature effect on the deformation behaviour of the specimens in Figs. 1 and 2 was assumed to be negligible. Similarly, the test temperature $150^{\circ} \mathrm{C}$ before highrate tension increased while straining and was very close to $180^{\circ} \mathrm{C}$ at the quasi-static tension (Fig. 3).
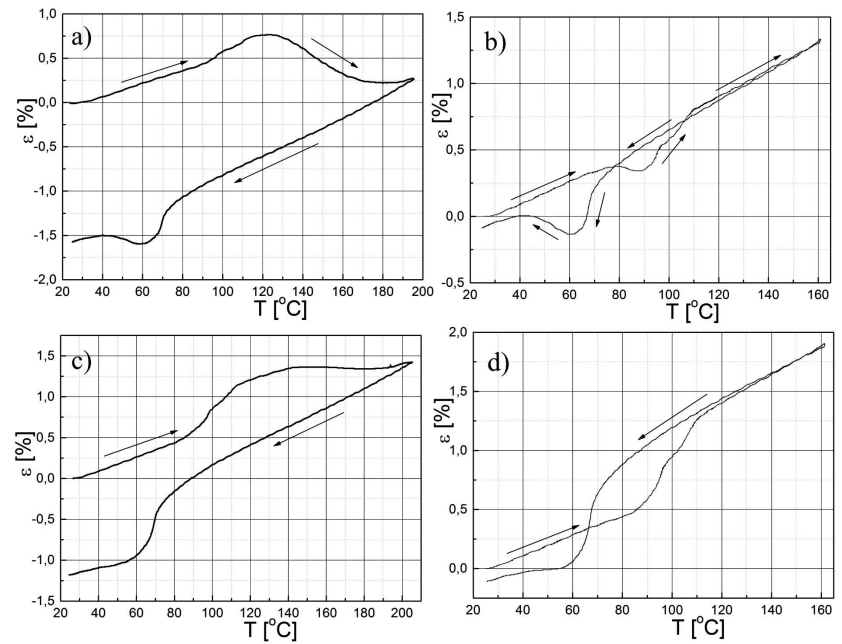

Fig. 1. Deformation behaviour of the unloaded NiTi specimens in the first $(a, c)$ and second $(b, d)$ heating/cooling cycles after quasi-static tension at $130{ }^{\circ} \mathrm{C}(\mathrm{a}, \mathrm{b})$ and at $150{ }^{\circ} \mathrm{C}(\mathrm{c}, \mathrm{d})$. Residual strain $\varepsilon_{\text {res }}=18.2 \%(\mathrm{a}, \mathrm{b})$ and $21.3 \%(\mathrm{c}, \mathrm{d})$.
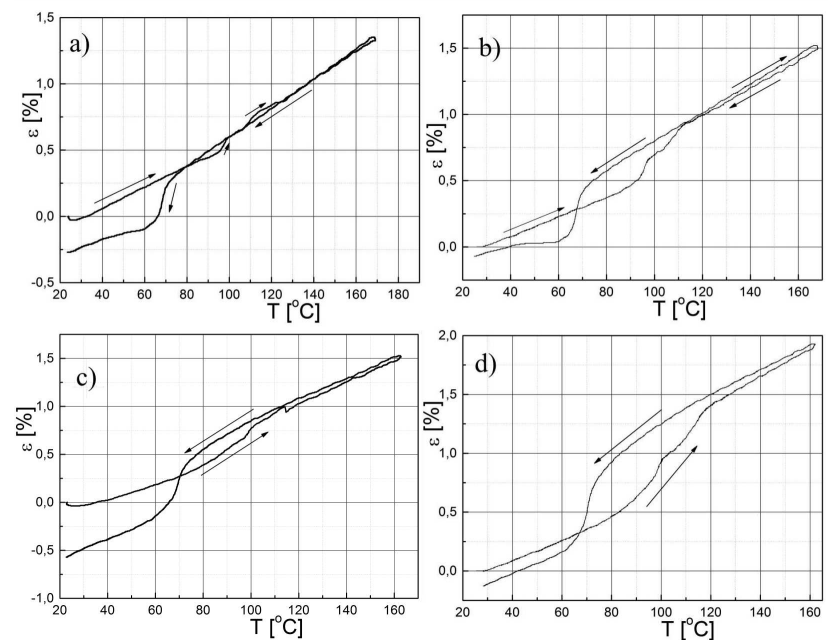

Fig. 2. Deformation behaviour of the unloaded NiTi specimens in the first $(\mathrm{a}, \mathrm{c})$ and second $(\mathrm{b}, \mathrm{d})$ heating/cooling cycles after high-rate tension at $110^{\circ} \mathrm{C}(\mathrm{a}, \mathrm{b})$ and $130{ }^{\circ} \mathrm{C}(\mathrm{c}, \mathrm{d})$. Residual strain $\varepsilon_{\mathrm{res}}=18.7 \%(\mathrm{a}, \mathrm{b})$ and $21.1 \%(\mathrm{c}, \mathrm{d})$.

As is clear from Fig. 1, the characteristic features of the deformation behaviour of the unloaded specimens in the 

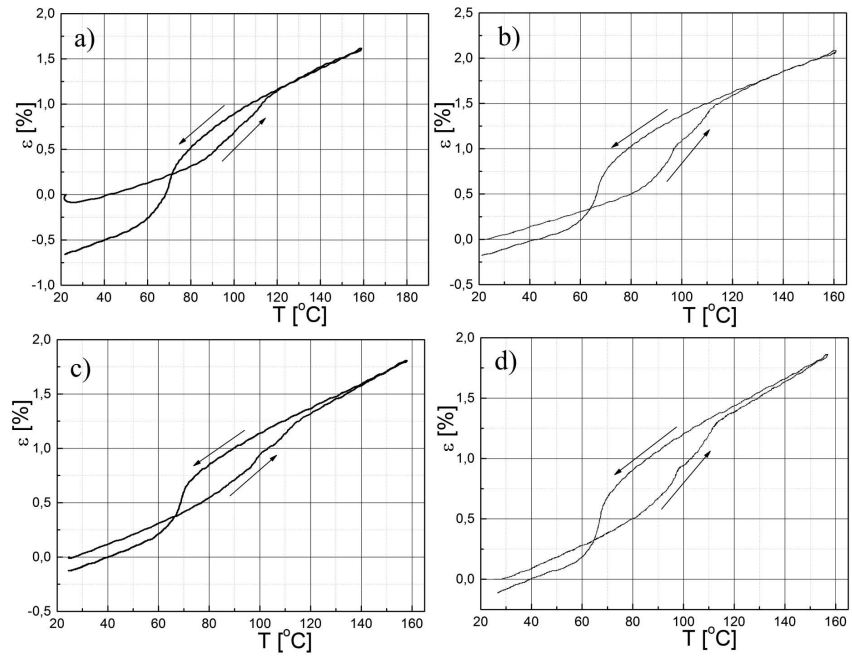

Fig. 3. Deformation behaviour of the unloaded NiTi specimens in the first $(a, c)$ and second $(b, d)$ heating/cooling cycles after quasi-static tension at $180^{\circ} \mathrm{C}(\mathrm{a}, \mathrm{b})$ and high-rate tension at $150{ }^{\circ} \mathrm{C}(\mathrm{c}, \mathrm{d})$. Residual strain $\varepsilon_{\text {res }}=17.6 \%(\mathrm{a}, \mathrm{b})$ and $21.9 \%(\mathrm{c}, \mathrm{d})$.

first heating/cooling cycles after quasi-static tension in the range of the $A_{\mathrm{f}}$ to $M_{\mathrm{d}}$ temperatures were a two-stage strain accumulation that preceded strain restoration on heating and the reversing strain behaviour on cooling, when the strain accumulation was initially opposite to the direction of external stress applied at tension and then coincided with it. The increase in test temperature towards the $M_{\mathrm{d}}$ temperature tended to decrease the magnitude of the strain restored and to increase the magnitude of the strain accumulated on heating, to increase the magnitude of the strain accumulated in the direction opposite to the direction of tension and to decrease the magnitude of the strain accumulated in the direction of tension on cooling (Fig. 1a and c).

It is worth noting that the features of the deformation behaviour above are typical for two distinct - martensitic and austenitic - types of two-way shape memory. Taking into consideration that quasi-static tension of the same alloy at temperatures between the $A_{\mathrm{s}}$ and $A_{\mathrm{f}}$ temperatures resulted in the shaping of martensitic two-way shape memory only [11], one may conclude that quasistatic tension at temperatures higher than the $A_{\mathrm{f}}$ temperature promoted the shaping of the austenitic two-way shape memory. The combination of both martensitic and austenitic two-way shape memory effects in the specimens tensioned in the range of the $A_{\mathrm{f}}$ to $M_{\mathrm{d}}$ temperatures was the reason for the observed reversing two-way shape memory effect.

Principally, the deformation behaviour on heating/cooling cycling of the unloaded specimens after highrate tension did not differ remarkably from the deformation behaviour of the specimens after quasi-static tension: the presence of strain accumulation on heating and reversing strain behaviour on cooling were similar (Fig. 2a). Moreover, after the high-rate tension at temperatures, which, taking into consideration the specimens' self-heating, corresponded with temperatures close to the $A_{\mathrm{f}}$ temperature (for example, high-rate tension of the specimens heated from room temperature up to $87^{\circ} \mathrm{C}$ increased their real temperature up to about $110-115^{\circ} \mathrm{C}$ ), the deformation behaviour revealed only strain restoration on heating and strain accumulation on cooling, i.e. the features of the martensitic two-way shape memory effect only. Thus, the above regularities of the deformation behaviour observed in the case of the quasi-static tension as the test temperature rose towards the $M_{\mathrm{d}}$ temperature, were valid for the high-rate tension as well. Just the transition from martensitic to austenitic two-way shape memory took place in the narrower temperature range (was more abrupt) in the case of high-rate tension. This observation additionally supports the earlier conclusion $[4,6]$ that the strain rate does not change the basic structural mechanisms of NiTi alloys' straining.

The decrease in the martensitic two-way shape memory effect and the increase in the austenitic effect, as the test temperature rose towards the $M_{\mathrm{d}}$ temperature, testified to the suppression of structural mechanisms responsible for the former and the enhancement of structural mechanisms responsible for the latter. Since both types of two-way shape memory effects are associated with martensitic transformations, it should be recalled that the 3-stage martensitic transformation of the NiTi alloy studied pointed at two martensitic transformations - B2 $\rightarrow B 19^{\prime}$ and $B 2 \rightarrow R \rightarrow B 19^{\prime}$, which took place in the precipitate-free grain interior and in the areas along the grain boundary with $\mathrm{Ni}_{4} \mathrm{Ti}_{3}$ precipitates, respectively. The decrease in the magnitude of the strain restored on heating, as well as the gradual decrease in the magnitude of strain accumulated in the direction of active tension on cooling (as the test temperature rose towards the $M_{\mathrm{d}}$ temperature), both correlated well with the familiar dependence of critical stress for $B 2 \rightarrow B 19^{\prime}$ transformation on temperature [12]: the higher the test temperature, the higher the critical stress. Along with the fact that strain restoration (associated with the straining of martensite) was absent after tension at temperatures higher than the $M_{\mathrm{d}}$ temperature, this allows us to suggest that the martensitic two-way shape memory was related to $B 2 \rightarrow B 19^{\prime}$ transformation.

The increase in the magnitudes of the strain accumulated on heating and of the strain accumulated on cooling in the direction opposite to the direction of active tension (with rising test temperature) could be associated with $B 2 \rightarrow R \rightarrow B 19^{\prime}$ transformation only. However, it remains unclear why the rise of test temperature promoted a higher degree of its realization. We could not find any information in the literature to confirm the decrease in critical stress for the $B 2 \rightarrow R$ reaction with rising temperature. Moreover, the experimental data presented in [13] testify to the steep increase in the dependence of critical stress for $R \rightarrow B 19^{\prime}$ transformation on temperature, thus excluding the feasibility of stress- 
induced $B 2 \rightarrow R \rightarrow B 19^{\prime}$ transformation. The realistic explanation of the increase in the magnitudes of the strains related to the austenitic two-way shape memory above could be that $B 2 \rightarrow R \rightarrow B 19^{\prime}$ transformation, the conclusion about which was based on the two-stage strain accumulation on heating in the first heating/cooling cycle after tension, really took place not on straining but on cooling only.

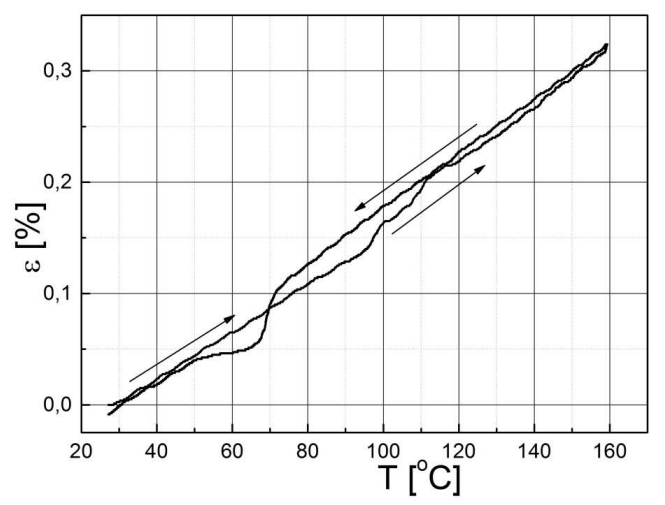

Fig. 4. Deformation behaviour of the unstrained initial NiTi specimen in the heating/cooling cycle through the range of martensitic transformation temperatures.

The role of straining at temperatures higher than the $A_{\mathrm{f}}$ temperature reduced to the creation of the necessary distortion in $B 2$ crystal lattice that assisted the formation of $R$ phase as the first step of the $B 2 \rightarrow R \rightarrow B 19^{\prime}$ reaction. Taking into consideration the similarity of specimens' loading in each set of experiments, the observed increase in strains associated with the $B 2 \rightarrow R \rightarrow B 19^{\prime}$ transformation, while the test temperature rose, can be explained by the increase in the structural stresses in the matrix around coherent $\mathrm{Ni}_{4} \mathrm{Ti}_{3}$ precipitates. This increase might be as a consequence of the different heat expansion of precipitates and matrix with rising temperature. It is worth noting that the maximum stresses created by the coherent $\mathrm{Ni}_{4} \mathrm{Ti}_{3}$ precipitates in the matrix are directed in the crystallographic direction of $\langle 111\rangle_{B 2}$, which coincides with the direction of the $c$-axis in the crystal lattice of $R$-phase. The increase in elastic distortion of $B 2$ crystal lattice in the crystallographic direction $\langle 111\rangle_{B 2}$ (as a result of the rising test temperature) assisted the external load to further stretch the parent cubic lattice along the $\langle 111\rangle$ diagonal and thus to create the $R$-phase crystal lattice. It should be emphasized that the specimens' cooling took place after unloading, when the elastic strain related to the external load was removed. Further development of the forward martensitic transformation and the shaping of functional properties were determined by the residual stresses only. The increase in strain associated with the austenitic two-way shape memory, while the tensile test temperature rose, allows us to conclude that these residual stresses were the result of the parent lattice plastic stretching. In fact, it means that $B 2 \rightarrow R$ transformation took place dur- ing tensile test, while further $R \rightarrow B 19^{\prime}$ was realized on cooling. The similar strain behaviour associated with the forward and reverse martensitic transformations, which was demonstrated by the unstrained and unloaded initial specimens during heating/cooling cycling through the interval of martensitic transformations (Fig. 4) [5], supports this conclusion.

The distinction between the deformation behaviours presented in Figs. 2a and 4 is only in the magnitudes of strains at corresponding stages (for instance, the strain associated with austenitic two-way shape memory after high-rate tension in Fig. 2a was about $0.320 \%$, while the same characteristic in Fig. 4 had a magnitude of about $0.07 \%$ ). It is clear that, in the absence of an external load, the distinctions in the strains accumulated on heating and cooling in both cases were determined by the distinct internal stresses. Since no strain was applied to the initial specimens, the transformation plasticity was determined by the structural stresses created by the coherent $\mathrm{Ni}_{4} \mathrm{Ti}_{3}$ precipitates only. The higher strains associated with the austenitic two-way shape memory after tension in the range of the $A_{\mathrm{f}}$ to $M_{\mathrm{d}}$ temperatures were obviously conditioned by higher residual stresses created by external load and preserved after unloading.
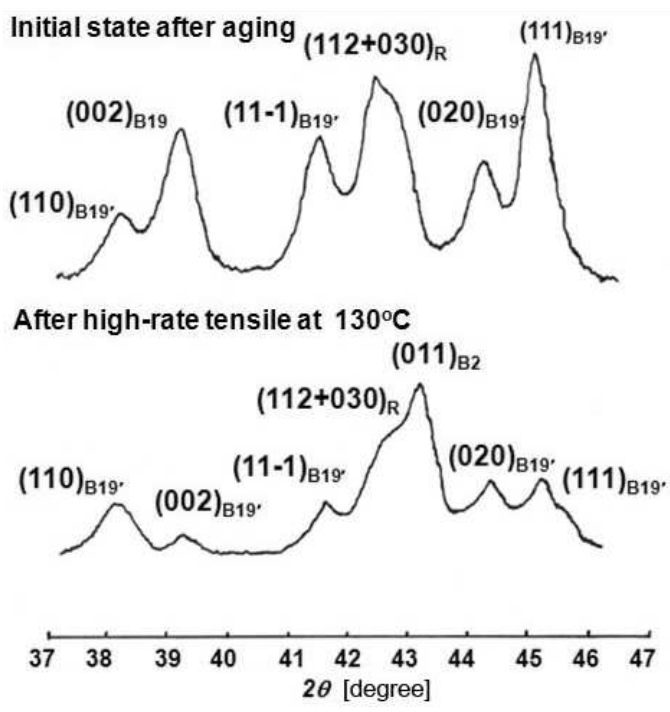

Fig. 5. X-ray patterns obtained from NiTi specimens in the initial state after ageing and followed by dynamic tension at $130^{\circ} \mathrm{C}$.

It should be noted that the lattice strain as a result of the above rearrangement of cubic lattice $(B 2 \rightarrow R$ transformation) was about $1 \%$, so the subsequent $R \rightarrow B 19^{\prime}$ transformation developed under low stress and did not accumulate large strain associated with transformation plasticity. Along with excluding most of the fraction of austenite (related to $B 2 \rightarrow B 19^{\prime}$ transformation) from participation in the shaping of austenitic two-way shape memory, this explains the low indices of the austenitic two-way shape memory effect. The X-ray pattern of a specimen after high-rate tension at $130^{\circ} \mathrm{C}$ (the real 
temperature was close to the $M_{\mathrm{d}}$ temperature) in Fig. 5, where the peak $(110)_{B 2}$ corresponding to $B 2$ phase presents, confirms the exclusion of the austenite in the grain interior from the process of austenitic two-way shape memory shaping. The presence of the residual austenite demonstrates that the tension at temperatures close to the $M_{\mathrm{d}}$ temperature led to the decrease in the $M_{\mathrm{f}}$ temperature of the $B 2 \rightarrow B 19^{\prime}$ transformation to lower than room temperature.

\section{Conclusion}

The conducted study showed that the strain rate has a negligible effect on the NiTi alloy's thermo-mechanical properties after tension in the fully austenitic state, compared with the tension of the same alloy in the martensitic or two-phase state, when the increase in strain rate tended to decrease its functional properties. The reason for this is the participation of plastic deformation at the earliest stages of the austenite straining, whatever strain rate is applied, which annihilates the basic distinction between quasi-static and high-rate tension - the participation of plastic deformation at different stages of straining. In the former, the plastic deformation joins the straining process at the final stages, when the reversible mechanisms of straining are completed, but participates actively along with the reversible mechanisms at the earliest stages of the latter.

The participation of plastic deformation at the earliest stages of the austenite straining at any strain rate is determined by two conditions. Firstly, the $B 2 \rightarrow R \rightarrow B 19^{\prime}$ transformation cannot be completed, since the dependence on temperature of the critical stress for $R \rightarrow B 19^{\prime}$ stress-induced transformation is very steep, starting from the $A_{\mathrm{f}}$ temperature, and only the first step of this reaction $-B 2 \rightarrow R$ transformation, the sense of which is the plastic stretching of $B 2$ cubic crystal lattice along the diagonal in the $\langle 111\rangle$ direction, is realized under external load. Secondly, the rise of test temperature is accompanied by an increase in critical stress for stress-induced $B 2 \rightarrow B 19^{\prime}$ transformation. Thus, while the test temperature increases from the $A_{\mathrm{f}}$ temperature towards the $M_{\mathrm{d}}$ temperature, more and more of the austenite undergoes plastic deformation from the very beginning of the straining.

The existence of distinct areas in quasi-equilibrium austenite - in the grain interior and in the grain boundary, and the distinctions in their straining processes are responsible for the shaping of martensitic and austenitic two-way shape memory effects, the simultaneous presence of which after tension in the range of the $A_{\mathrm{f}}$ to $M_{\mathrm{d}}$ temperatures determines the reversing shape memory effect. By regulating the tensile test temperature in this range, one may regulate the participation of each type of two-way shape memory, which determines the length of the reversing movements of the special NiTi actuators. The tension at temperatures higher than the $M_{\mathrm{d}}$ temperature results in the shaping of austenitic two-way shape memory only, the magnitude of which is independent of the strain rate.

\section{Acknowledgments}

The authors are grateful to Russian Foundation for Basic Research (grant \#13-01-00050) and Saint-Petersburg State University (grant \# 6.38.74.2012) for supporting this research.

\section{References}

[1] A. Razov, Phys. Met. Metall. 97, Suppl. 1, 97 (2004).

[2] V. Torra, G. Carreras, S. Casciati, P. Terriault, Smart Struct. Syst. 13, 353 (2014).

[3] A. Bragov, A. Galieva, V. Grigorieva, A. Danilov, A. Konstantinov, A. Lomunov, A. Motorin, E. Ostropiko, A. Razov, Mater. Sci. Forum 738-739, 326 (2013).

[4] A. Bragov, A. Danilov, A. Konstantinov, A. Lomunov, A. Motorin, A. Razov, Phys. Met. Metall. 116, 385 (2015).

[5] A. Razov, A. Motorin, G. Nakhatova, J. Alloys Comp. 577, Suppl. 1, 164 (2013).

[6] A. Danilov, A. Razov, in: Shape Memory Alloys: Properties, Technologies, Opportunities, Eds. N. Resnina, V. Rubanik, Trans Tech Publications, Pfaffikon, Switzerland 2015, p. 457.

[7] J. Khalil Allafi, X. Ren, G. Eggeler, Acta Mater. 50, 793 (2002).

[8] J. Khalil-Allafi, A. Dlouhy, G. Eggeler, Acta Mater. 50, 4225 (2002).

[9] A.M. Bragov, A.K. Lomunov, Int. J. Impact Eng. 16, 321 (1995).

[10] S.-Q. Shi, J.-Y. Chen, X.-L. Dong, L.-L. Wang, S.P. Belyaev, A.E. Volkov, N.F. Morozov, A.I. Razov, Explos. Shock Waves 21, 168 (2001).

[11] A. Bragov, A. Danilov, A. Konstantinov, A. Lomunov, A. Motorin, A. Razov, Mater. Today: Proc.2, Suppl. 3, S961 (2015).

[12] S. Miyazaki, K. Otsuka, Y. Suzuki, Scr. Metall. 15, 287 (1981).

[13] S. Miyazaki, S. Kimura, K. Otsuka, Philos. Mag. A 57, 467 (1988). 